Discussion Paper No. 04-34

\title{
Returns to Education
} and Individual Heterogeneity

Michael Maier, Friedhelm Pfeiffer and Winfried Pohlmeier

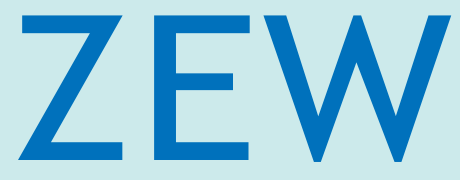

Zentrum für Europäische Wirtschaftsforschung $\mathrm{GmbH}$

Centre for European

Economic Research 
Discussion Paper No. 04-34

\title{
Returns to Education and Individual Heterogeneity
}

\author{
Michael Maier, Friedhelm Pfeiffer \\ and Winfried Pohlmeier
}

Download this ZEW Discussion Paper from our ftp server:

\section{ftp://ftp.zew.de/pub/zew-docs/dp/dp0434.pdf}

Die Discussion Papers dienen einer möglichst schnellen Verbreitung von neueren Forschungsarbeiten des ZEW. Die Beiträge liegen in alleiniger Verantwortung der Autoren und stellen nicht notwendigerweise die Meinung des ZEW dar.

Discussion Papers are intended to make results of ZEW research promptly available to other economists in order to encourage discussion and suggestions for revisions. The authors are solely responsible for the contents which do not necessarily represent the opinion of the ZEW. 


\section{Non technical summary}

Two major issues concerning the impact of schooling on earnings have been raised in the recent empirical literature on human capital investments. First, education as the individual's choice parameter is an endogenous variable in the standard earnings function. Coefficient estimates on schooling can only be interpreted as causal effects of schooling on earnings if individuals have been randomly assigned to different schooling levels. Therefore standard least squares estimates are only of an explorative nature and their usefulness with respect to policy recommendations is limited. Second, as a choice parameter the schooling levels are determined by individual's observed and unobserved marginal benefits and costs of schooling. Thus, the return of an additional year of schooling varies across individuals.

In order to assess the causal effect of education on earnings we adopt the concept of the average treatment effect (ATE) developed in the econometric evaluation literature. This is used to quantify the expected earnings difference between two otherwise identical individuals if they had been assigned randomly to $S$ and $S+1$ years of schooling, respectively. Contrary to previous studies on the ATE in standard earnings functions which rest on a control function approach we apply the conditional mean independence (CMI) approach to identify the ATE of education.

Our estimate of the average causal effect of an additional year of schooling is $8.7 \%$, which is close to the two stage least square estimate of the rate of return in a traditional fixed coefficient earnings function. Heterogeneity in the returns does matter and the monetary benefits of an additional year of schooling vary largely across the population. For 20 to $30 \%$ of the male workers in our sample, an additional year of schooling yields negative returns. For more than $25 \%$, the returns are above $15 \%$. Negative return rates may result from restricted entry into the labour market in which case education is a mean of bridging over waiting queues in times of unemployment, for example. The large positive returns may result from individual differences in learning abilities, educational costs and educational quality, among other reasons.

Additional results seem to suggest that the law of diminishing returns to investments in human capital does not necessarily hold for all persons and all educational institutions at the chosen levels of schooling. If this interpretation is valid then there might exist a variety of hitherto not fully exploited investment opportunities in schooling for significant groups of individuals in Germany. 


\title{
Returns to Education and Individual Heterogeneity
}

\author{
by \\ Michael Maier (University of Konstant, ZEW), \\ Friedhelm Pfeiffer (University of Mannheim, ZEW) and \\ Winfried Pohlmeier (University of Konstanz, CoFE, ZEW)
}

\begin{abstract}
In this paper, human capital investments are evaluated by assuming heterogeneous returns to education. We use the potential outcome approach to measure the causal effect of human capital investments on earnings as a continuous treatment effect. Empirical evidence is based on a sample of West German full-time employed males from the "BIBB/IAB-Strukturerhebung 1998/99." Our estimate of the average treatment effect of an additional year of schooling (ATE) amounts to 8.7\%, which is quite similar to conventional instrumental variable estimates.
\end{abstract}

Keywords: potential outcome approach, marginal benefits and costs of schooling, unobserved heterogeneity, unemployment, average treatment effect.

Acknowledgement: Financial support by the DFG through research group "Heterogeneous labor" at the University of Konstanz and the ZEW, is gratefully acknowledged. We would like to thank Andreas Ammermüller, Markus Jochmann, Charlotte Lauer, Andrea Weber and seminar participants at the University of Konstanz and the ZEW for very valuable comments. The usual disclaimer applies. 


\section{Introduction}

Two major issues concerning the impact of schooling on earnings have been raised in the recent empirical literature on human capital investments. ${ }^{1}$ First, education as the individual's choice parameter is an endogenous variable in the standard earnings function. Coefficient estimates on schooling can only be interpreted as causal effects of schooling on earnings if individuals have been randomly assigned to different schooling levels. Therefore standard least squares estimates are only of an explorative nature and their usefulness with respect to policy recommendations is limited. Second, as a choice parameter the individual's schooling level is determined by the individual's observed and unobserved marginal benefits and costs of schooling. Thus, the return of an additional year of schooling varies across individuals.

In order to assess the causal effect of education on earnings we adopt the concept of the average treatment effect (ATE) developed in the econometric evaluation literature. This is used to quantify the expected earnings difference between two otherwise identical individuals if they had been assigned randomly to $\mathrm{S}$ and $\mathrm{S}+1$ years of schooling, respectively. Contrary to previous studies on the ATE in standard earnings functions which rest on a control function approach we apply the conditional mean independence (CMI) approach to identify the ATE of education. ${ }^{2}$

Our paper is organised as follows: In Section 2, we develop the idea of random returns to education based on Card's schooling model (Card, 1999). Following Wooldridge (2002), we identify the average treatment effect via conditional mean independence assumptions and show that the ATE for the continuous treatment variable schooling can be estimated by means of auxiliary regressions. Section 3 describes the data and provides some information on the institutional settings in Germany. Our empirical findings are presented in Sections 4 and 5, while Section 6 concludes with an outlook on future research.

\section{The CMI Approach}

Numerous studies on the returns to education emphasize that schooling is a choice variable depending on observable and unobservable factors that determine the individual's marginal costs and benefits of schooling. For the econometrician, this

\footnotetext{
${ }^{1}$ See for example Card (1999), Heckman (2003), and Wooldridge (2002).

${ }^{2}$ Maier et al. (2003) use this approach to assess the effect of overeducation on earnings.
} 
implies that returns to schooling is a random variable correlated with the determinants; i.e. the returns to schooling vary across individuals. These basic features are captured in Card's $(1999,2001)$ model of schooling and earnings which we will use as a specification device. The individual is assumed to choose the optimal amount of schooling, $\mathrm{S}$ and earnings, $\mathrm{Y}$ that maximize his lifetime utility depending on earnings and the disutility of schooling, $\varphi(S)$ :

$\max U(S, Y)=\ln Y-\varphi(S)$ with $\varphi^{\prime}(S)>0$ and $\varphi^{\prime \prime}(S)>0$.

Let the benefits of schooling (schooling-earnings relationship) be $\mathrm{Y}=\mathrm{Y}(\mathrm{S})$ with $\mathrm{Y}^{\prime}(\mathrm{S})>0$. This yields the first order conditions

$$
\frac{\mathrm{Y}^{\prime}(\mathrm{S})}{\mathrm{Y}(\mathrm{S})}=\varphi^{\prime}(\mathrm{S})
$$

A linear log earnings function for schooling arises if marginal benefits are constant $^{3}$ :

$M B \equiv \frac{Y^{\prime}(S)}{Y(S)}=\beta$.

If marginal costs are linear in schooling, then:

$M C \equiv \varphi^{\prime}(S)=\gamma+\kappa S, \quad \kappa>0$.

Optimal schooling is given by

$S=\frac{\beta-\gamma}{\kappa}$.

Integration of the marginal benefit function (2.3) yields a log linear earnings function with random coefficients, an individual specific intercept and an individual specific slope coefficient:

$\ln Y=\alpha+\beta S$.

3 Assuming a linear marginal benefit function results in a log earnings function that contains an additional quadratic schooling term. 
Intercept coefficient $\alpha$ captures the absolute productivity (ability) advantages of the agent. Observable factors and unobserved heterogeneity in the absolute and marginal benefits of schooling as well as factors driving the marginal costs of schooling enter the earnings function through the coefficients $\alpha, \beta$ and $\gamma$, respectively. Let $\alpha$ be presented by the linear predictor function

$\alpha=\alpha_{0}+X_{1}^{\prime} \alpha_{1}+\eta_{\alpha}$,

where $X_{1}$ is a vector of observables and the random variable $\eta_{\alpha}$ captures unobserved heterogeneity in the absolute productivity term. Likewise, marginal productivity may depend on the same set of factors:

$$
\beta=\beta_{0}+X_{1}^{\prime} \beta_{1}+\eta_{\beta},
$$

while marginal cost depends on the $X_{1}$ variables as well as on additional cost driving factors $X_{2}$ :

$\gamma=\gamma_{0}+X_{1}^{\prime} \gamma_{1}+X_{2}^{\prime} \gamma_{2}+\eta_{\gamma}$

Inserting (2.7) - (2.9) in the schooling equation (2.5) yields a reduced form of the schooling equation:

$$
\begin{aligned}
S & =\frac{1}{\kappa}\left[\left(\beta_{0}-\gamma_{0}\right)+X_{1}^{\prime}\left(\beta_{1}-\gamma_{1}\right)-X_{2}^{\prime} \gamma_{2}+\eta_{\beta}-\eta_{\gamma}\right] \\
& =\pi_{0}+X_{1}^{\prime} \pi_{1}+X_{2}^{\prime} \pi_{2}+\xi
\end{aligned}
$$

Note that the returns of an additional year of schooling now is a random variable depending on the level of schooling and the marginal costs of schooling; i.e., the returns to schooling vary across the population. The average treatment effect (ATE), of an additional year of schooling is the mean across all individual returns of an additional year of schooling:

$$
A T E=E[E[\ln Y \mid S=s+1, \alpha, \beta]-E[\ln Y \mid S=s, \alpha, \beta]]=E[\beta] .
$$

Similar to the binary treatment effect literature for the case of a continuous treatment, one can distinguish between two approaches to the evaluation problem. Garen (1984), Heckman and Vytlacil (1998) and Wooldridge (1997) propose an IV or control function approach that makes use of control functions such as (2.7) and (2.8) to estimate the ATE from the reduced forms for earnings and schooling. The major drawback of this approach is the limited availability of reasonable exclusion 
restrictions (instruments) that differentiate the causal treatment effect from the selection effect. Here, we follow a suggestion from Wooldridge (2002, Chapter 18.5). The ATE is estimated in a random coefficient framework by assuming conditional mean independence. Under this asumption treatments can be ignored conditional on a set of covariates. The ATE can be identified if the following assumptions hold (ignorability conditions):

Identifying Assumptions for the ATE (Wooldridge (2002), p.639):

(i) Equation (2.6) holds.

(ii) For a set of covariates $\mathrm{X}$, the following redundancy assumption holds:

$$
E[\ln Y \mid S, \alpha, \beta, X]=E[\ln Y \mid S, \alpha, \beta]
$$

(iii) Conditional on $\mathrm{X}, \alpha$ and $\beta$ are redundant in the first two conditional moments of S:

$$
E[S \mid X, \alpha, \beta]=E[S \mid X] \text { and } \mathrm{v}[\mathrm{S} \mid \mathrm{X}, \alpha, \beta]=V[S \mid X]>0
$$

Identification condition (ii) obviously holds since the control variable $\mathrm{X}$ enters the earnings function through $\alpha, \beta$ and $\mathrm{S}$ only. The linear predictor specification used for illustrative purposes in (2.7) and (2.8) is not required to identify the ATE. In fact, the conditional mean independence approach uses identification conditions different from the control function approaches in correlated random coefficient models. Identification condition (iii) denotes that conditional on the controls, expected schooling is mean independent of $\alpha$ and $\beta$. Thus no new information is gained in projecting schooling if there are sufficient controls. This is the crucial identification condition (ignorability condition) needed to identify the ATE.

Proposition 2.1 (ATE) (Wooldridge (2002), p.639):

Under the identifying assumptions the average treatment effect for all $\mathrm{X}$ in the relevant population is given by

$$
E[\beta]=E\left[\frac{\operatorname{Cov}[S, \ln Y \mid X]}{V[S \mid X]}\right] .
$$

In the following analysis, we estimate $\mathrm{V}[\mathrm{S} \mid \mathrm{X}]$ and $\operatorname{Cov}[\mathrm{S}, \ln \mathrm{Y} \mid \mathrm{X}]$ by means of linear regression. Replacing the population parameters with the regression 
estimates yields a consistent estimate of the average treatment effect under the assumption of independent, identically distributed observations:

$$
\hat{E}[\beta]=\frac{1}{n} \sum_{i=1}^{n} \frac{\operatorname{Cov}\left[S_{i}, \ln Y_{i} \mid X_{i}\right]}{\hat{V}\left[S_{i} \mid X_{i}\right]} .
$$

Note that contrary to the instrumental variable or control function approach the CMI approach does not require exclusion restrictions for instrumental variables in such a way that the instruments drive the selection process (choice of the optimal years of schooling). Rather, they are uncorrelated with the error term of the structural equation. Since the ATE is nothing but the mean of the ratio of second moments and cross-moments of schooling and earnings conditional on $\mathrm{X}$, more insights into the causal effects of schooling can be obtained by analyzing other distributional properties of this ratio in addition to the mean.

\section{Data}

Our empirical study is based on a sample of full-time employed male workers from the so-called BIBB/IAB survey on educational and vocational attainment and career (BIBB/IAB (1999)), conducted in 1999. ${ }^{4}$ The 1999 survey contains comprehensive information on the number of years spent in the educational and vocational education system in Germany. In particular, our data contain extensive information on the successful completion of schooling levels (basic schooling, vocational and university education) and the actual years spent in the educational system to obtain the degree. Hence, our definition of the schooling variable is more closely related to the definition of an input variable than the standard definition using either the minimum years required by the individual to receive his/her highest

${ }^{4}$ The BIBB/IAB survey is a $0.1 \%$ representative survey of German workers which has been conducted every five to six years since 1979. The objective of the survey is to supply "differentiated, actual data on workers in Germany, their qualifications and working conditions" (Jansen and Stooss, 1993; Dostal and Jansen, 2002). BIBB: Federal Institute for Vocational Training, or Bundesinstitut für Berufsbildung, IAB: Institute for Labour Market and Occupational Research of the Federal Labour Office, or Institut für Arbeitsmarkt- und Berufsforschung der Bundesanstalt für Arbeit. Data collection is organized jointly by the two organisations: BIBB and IAB. The data are processed and documented by the Central Archive for Empirical Social Research, or Zentralarchiv für empirische Sozialforschung (ZA), Cologne. Neither the BIBB, the IAB nor the ZA take any responsibility for the analysis or the interpretation of the data presented here. 
educational attainment or the average years of schooling necessary to attain a degree.

Table 1 contains selected summary statistics on the number of observations, on the number of schooling and on earnings for four different educational groups: workers without any formal occupational degree, workers with an apprenticeship degree (Geselle), workers with senior craftsmen qualifications (Meister) or a degree from a university of applied sciences (Fachhochschule) and workers with at least a university degree. ${ }^{5}$ The overall years of standard schooling for these groups are 10 , 13, 15-16 and 18. The actual number of schooling spent to capture a university degree are 1.7 years higher than standard years. For the quantitative important group of workers with an apprenticeship degree, actual and standard years are not that different.

Table 1: Summary Statistics of Schooling and Earnings by Skill Group

\begin{tabular}{lrrrrrr}
\hline \hline Sample & \multicolumn{2}{c}{ Observations } & \multicolumn{2}{c}{ Earnings [DM] } & \multicolumn{2}{c}{ Schooling [years] } \\
& Freq. & Percent & mean & std.dev. & mean & std.dev. \\
& 7,722 & 100 & 4,697 & $1,986.4$ & 14.3 & 3.5 \\
Overall sample & 762 & 9.9 & 3,689 & $1,667.7$ & 10.6 & 2.4 \\
Unskilled & 4,988 & 64.6 & 4,302 & $1,572.0$ & 13.7 & 2.5 \\
$\begin{array}{l}\text { Vocational } \\
\text { training }\end{array}$ & 1,330 & 17.2 & 5,627 & $2,017.5$ & 16.5 & 3.6 \\
$\begin{array}{l}\text { Foreman, } \\
\begin{array}{l}\text { senior } \\
\text { craftsman }\end{array}\end{array}$ & & & & & & \\
$\begin{array}{l}\text { University } \\
\text { graduate }\end{array}$ & 642 & 8.3 & 7,028 & $2,628.3$ & 19.7 & 2.7 \\
\hline \hline
\end{tabular}

Data source: BIBB/IAB 1999; own calculation; for definitions and sample selection see text.

For our analysis a sample of German male workers is selected (that is, we exclude women, self-employed and part-time employed males) from the 1989/99 survey. We concentrate on full-time male workers because men by and large have an inelastic labour supply and we can disregard selection into the labour force. Our earnings variable refers to the natural logarithm of monthly earnings before taxes.

${ }^{5}$ For a short introduction into the German educational system compare for example Blechinger and Pfeiffer (2000). 
We end up with 7,722 observations. For more details on data selection, see also Maier et al. (2003). Summary statistics of the covariates are presented in Table 6 in the Appendix.

\section{Empirical Findings}

As a benchmark for our estimates of the ATE, we first present the results of more traditional two-stage least squares estimates of the earnings function assuming homogenous returns to schooling (Table 2 and 3). The instruments used are the unemployment rate at graduation and its interaction terms with age and the squared age variable, which yield three overidentifying restrictions. The reasoning behind the use of these instruments lies in some specific institutional features of the German vocational system. By opting for the elementary vocational year (Berufsgrundbildungsjahr), youths, especially those without an apprenticeship training position, have the opportunity to prepare for vocational training by attending a full-time school year (optional as part-time school). The preparation year for vocational training (Berufsvorbereitungsjahr) basically serves the same purpose as the elementary vocational year, but in a somewhat broader sense. It prepares youths without an apprenticeship position for vocational training. ${ }^{6}$ If unemployment reflects opportunity costs, an individual is more likely to stay in the educational system if employment prospects are low. This argument seems particularly relevant for the case of Germany where tuition and fees for general schooling and vocational training are rare exceptions or negligible. Note, that our instruments are defined at the macro-level. Carneiro and Heckman (2002) show that instruments defined at the individual level such as the educational background of the parents and proximity to school are correlated with individual ability and thus cannot serve as valid instruments.

Table 2 presents the reduced form estimates for the schooling equation. Given the large value of the F-Test (195.84) we can reject the null of weak instruments in terms of the relative 2SLS bias (>10\%) and the actual size of the 2SLS t-test (> $15 \%$ ) according to the critical values presented in Stock et al. (2002). The unemployment rate at graduation has a significant impact on the schooling level, and its impact varies across cohorts. Our specification explains $36 \%$ of the variation in schooling in the sample. Using the Hausman test (auxiliary regression specification), the hypothesis that schooling can be treated as an exogenous explanatory variable was rejected.

${ }^{6}$ Franz et al. (2000) study the impact of vocational training on youth unemployment duration. 
Table 2: Reduced Form Estimates of the Schooling Equation

\begin{tabular}{lcc}
\hline \hline Variable & $\beta$ & t value \\
\hline Experience & -.330 & -16.65 \\
Experience squared & -.003 & -4.96 \\
Age & .267 & 2.43 \\
Age squared & .003 & 2.12 \\
Unemployment ratio at graduation & -.331 & -1.10 \\
Unemployment ratio at graduation * Age & .028 & 1.79 \\
Unemployment ratio at graduation * Age squared & .000 & -1.41 \\
Constant & 6.685 & 2.94 \\
\hline
\end{tabular}

$\mathrm{N}=7,722 ; \mathrm{F}(22,7699)=195.84 ; \mathrm{R}^{2}=0.36$

Additional controls: sectoral dummies, regional dummies, firm size and a dummy variable for handicapped workers.

Dependent variable: Years of schooling.

Data source: BIBB/IAB 1999; own estimates.

The 2SLS estimates of the fixed coefficient earnings function are given in Table 3. In addition to the typical covariates schooling, experience and experience squared, sectoral dummies, regional dummies, firm size and a dummy variable for handicapped workers are used as additional controls. The return to an additional school year is $8.3 \%$, which is in line with former estimates for Germany (see for example Pfeiffer, 2000). Ignoring the endogeneity of schooling by estimating the equation using ordinary least squares results in a lower estimate of $4.2 \%$ (see Maier et al. (2003)). These differences confirm the international evidence that the return rates obtained from instrumental variable estimators often are above the ones from ordinary least squares estimates (see Card, 1999).

The estimates of the expected rate of return to an additional year of schooling based on the CMI approach are reported in Table 4. In the first line of Table 4, we report the ATE using all observations. Outliers turn out to have a significant effect on the reported ATE values. Therefore, the second line presents estimates based on a trimmed sample, where observations below the 1\% and above the $99 \%$ ATE quantiles were dropped. Trimming obviously leads to more plausible estimation results. 
Table 3: 2SLS Estimates of the Earnings Equation

\begin{tabular}{lcc}
\hline \hline Variable & $\beta$ & $\mathrm{t}$ value \\
\hline Schooling & .083 & 33.57 \\
Experience & .030 & 18.09 \\
Experience squared & .000 & -9.48 \\
Handicapped & -.039 & -1.88 \\
Constant & 6.920 & 159.9 \\
\hline
\end{tabular}

$\mathrm{N}=7,722 ; \mathrm{F}(18,7703)=132.19 ; \mathrm{R}^{2}=0.236$

Hausman test $(\mathrm{N}(0,1))=20.76$

Additional controls: sectoral dummies, regional dummies, firm size dummies.

Dependent variable: Logarithm of wage

Data source: BIBB/IAB 1999, own estimates

The CMI approach reveals an average treatment effect of an additional year of schooling (ATE) at $8.7 \%$ which is significantly different from zero. This estimate does not differ much from the 2SLS results reported above. Angrist and Imbens (1995) show that for models with variable treatment intensity, the 2SLS estimator identifies a weighted average of the treatment effect in the population whose educational attainment was changed by the instrument (local average treatment effect). Hence, there is no reason to expect ex ante quantitatively similar estimates. Using a control function approach Deschenes (2002) obtained a value of $16.2 \%$ for ATE based on US-data, which slightly lies below his 2SLS estimate.

The quantiles of the individual return rates reported in Table 4 reveal that the impact of educational attainment on earnings is far from being homogeneous. For a quarter of the individuals, the causal return rate is more than $15.6 \%$, and for the $90 \%$ quantile, it is $28.3 \%$. On the other hand, for a quarter of the individuals there are very low or even negative causal return rates. For example, negative return rates may result from a restricted entry into the labour market, in which case education serves as means of bridging over waiting queues in times of unemployment. They can be the result of a suboptimal matching between heterogenous students and teaching institutions as well. 
Table 4: Estimates of the ATE

\begin{tabular}{llllllll}
\hline \hline$\hat{\mathrm{E}}[ß]$ & t-value & \multicolumn{2}{l}{ Quantiles } & & & & \\
& & $10 \%$ & $25 \%$ & $50 \%$ & $75 \%$ & $90 \%$ & \\
& & & & & & & \\
\hline 1.060 & 1.22 & -.103 & .005 & .076 & .158 & .294 & without trimming \\
0.087 & 29.94 & -.091 & .007 & .076 & .156 & .283 & trimmed \\
\hline \hline
\end{tabular}

Data source: BIBB/IAB 1999; own estimates.

More descriptive evidence on the distribution of the heterogenous returns is given by the kernel density estimate depicted in Figure 1. The estimated distribution of $\beta$ turns out to be slightly skewed to the right.

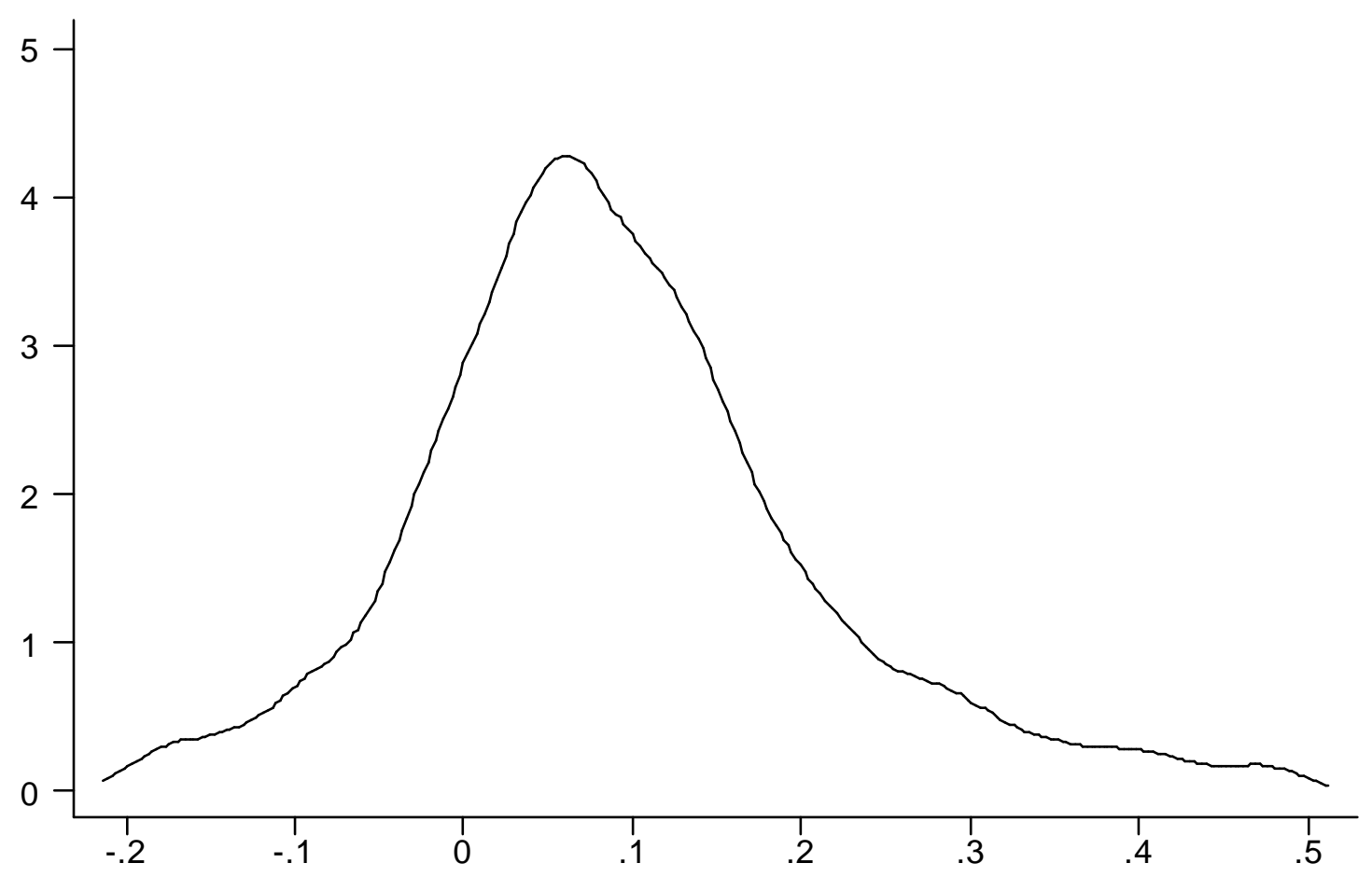

Figure 1: Kernel density estimates of the ATE 


\section{Characteristics of workers with lower and higher returns to schooling}

For economic policy reasons it is important to know who benefits from education. To get some empirical insights into this question, the sample has been divided into workers with a ATE-value above the median, and workers below the median ATEvalue. Table 5 presents descriptive statistics on some relevant socio-economic characteristics in the two sub-samples. The differences in the two samples suggests that on average in the group with higher returns to education workers have acquired more years of schooling, are better qualified (the share of university graduates for example is $12 \%$ in the high returns group compared to only $4 \%$ in the low returns group) and do have higher earnings. These statistics seem to suggest that the law of diminishing returns to investments in human capital does not necessarily hold for all persons and all educational institutions at the chosen levels of schooling. If this interpretation is valid then there might exist a variety of hitherto not fully exploited investment opportunities in schooling for significant groups of individuals in Germany.

Table 5: Socio-economic characteristics of two groups of workers

\begin{tabular}{lrrr}
\hline \hline Variables & \multicolumn{2}{c}{ Estimated ATE } & t-value of difference \\
& below median & above median & \\
\hline Schooling & 13.92 & 14.76 & -10.65 \\
Earnings & 4576.17 & 4817.15 & -5.34 \\
Age & 37.53 & 37.40 & .68 \\
Qualification: & & & \\
Unskilled & .11 & .09 & 3.97 \\
Vocational Training & .68 & .61 & 7.16 \\
Foremen etc. & .16 & .18 & -2.53 \\
University graduates & .04 & .12 & -13.34 \\
\hline \hline
\end{tabular}

Data source: BIBB/IAB 1999; own calculations. 


\section{Concluding remarks}

In this paper, the returns of human capital investments are assessed based on the potential outcome for continuous treatments. The estimate of the causal effect of schooling on earnings is based on the CMI approach, taking into account heterogeneity of costs and benefits among individuals. Our estimate of the average causal effect of an additional year of schooling is $8.7 \%$, which is close to the two stage least square estimate of the rate of return in a traditional fixed coefficient earnings function. Heterogeneity in the returns does matter and the monetary benefits of an additional year of schooling vary largely across the population. For 20 to $30 \%$ of the male workers in our sample, an additional year of schooling yields negative returns. For more than $25 \%$, the returns are above $15 \%$. Negative return rates may result from restricted entry into the labour market in which case education is a mean of bridging over waiting queues in times of unemployment, for example. The large positive returns may result from individual differences in learning abilities, educational costs and educational quality, among other reasons.

Since there is little practical experience with the CMI approach applied to correlated random coefficient models, our results, although plausible, should be treated with caution. More evidence based on other data is clearly needed to evaluate the new econometric technique. For policy analysis, other treatment effects such as the effect of treatment on the treated, the treatment on the nontreated and the local average treatment effect should also be evaluated. Clearly, more research is needed to disentagle individual heterogeneity and institutional diversification for the economic returns of education. 


\section{References}

Angrist, J. D., and G. W. Imbens (1995): Two-Stage Least Squares Estimation of Average Causal Effects in Models with Variable Treatment Intensity, Journal of the American Statistical Association, 90, 431 - 442.

BIBB/IAB (1999): Erwerb und Verwertung beruflicher Qualifikationen von Erwerbstätigen, BIBB/IAB Strukturerhebung 1998/99. Erhebungsmaterialien zur Hauptstudie. BIBB, Berlin.

Blechinger, D., and F. Pfeiffer (2000): Technological Change and Skill Obsolescence: the Case of German Apprenticeship Training, in: Education and Training in a Knowledge-Based Economy, ed. by H. Heijke, and J. Muysken, St. Martin's Press, New York, 243-276.

Card, D. (1999): The Causal Effect of Education and Earnings, in: Handbook of Labor Economics, 3, ed. by O. Aschenfelter and D. Card, North-Holland, 1801-1863.

Card, D. (2001): Estimating the Returns to Schooling: Progress on Some Persistent Econometric Problems, Econometrica, 69 (5), 1127-1160.

Carneiro, P., and J. Heckman (2002): The Evidence on Credit Constraints in PostSecondary Schooling, Economic Journal, 112, 705-734.

Deschenes, O. (2002): Estimating the Effects of Family Background on the Return to Schooling, paper presented at the Econometric Society European Meeting (ESEM), Venice, August 2002.

Dostal, W., and R. Jansen (2002): Qualifikation und Erwerbssituation in Deutschland - 20 Jahre BIBB/IAB Erhebungen, Mitteilungen aus der Arbeitsmarkt- und Berufsforschung, 35 (2), 232-253.

Franz, W., J. Inkmann, W. Pohlmeier, and V. Zimmermann (2000): Young and Out in Germany: On Youths' Chances of Labor Market Entrance in Germany, in: Youth Employment and Joblessness in Advanced Countries, ed. by D. G. Blanchflower, and R. B. Freeman, 381-425. The University of Chicago Press.

Garen, J. (1984): The Returns to Schooling: A Selectivity Bias Approach with a Continous Choice Variable, Econometrica, 52, 1199 - 1218.

Heckman, J. (2003): Fifty Years of Mincer Earnings Regressions, NBER Working Paper 9732.

Heckman, J. J., and E. Vytlacil (1998): Instrumental Variables Methods for the Correlated Random Coeffcient Model: Estimating the Rate of Return to 
Schooling When the return is Corelated with Schooling, Journal of Human Resources, 23, 974-987.

Jansen, R., and F. Stooss (1993): Qualifikation und Erwerbssituation im geeinten Deutschland: BIBB/IAB Erhebung 1991/92. Bundesinstitut fuer Berufsbildung, Berlin.

Maier, M., F. Pfeiffer, and W. Pohlmeier (2003): Overeducation and Individual Heterogeneity, in: Overeducation in Europe: Current issues in theory and policy, ed. by F. Büchel, A. de Grip, and A. Mertens. Edward Elgar (in press).

Pfeiffer, F. (2000): Aufwand und Ertrag: Daten und Fakten zur Bildung in Deutschland und in Europa, in Rohstoff Bildung, ed. by K. Morath, Frankfurter Institut - Stiftung Marktwirtschaft und Politik, 11-26.

Stock, J. H., J. H. Wright, and M. Yogo (2002): A Survey of Weak Instruments and Weak Identification in Generalized Method of Moments, Journal of Business and Economic Statistics, 20, 518-529.

Wooldridge, J. M. (1997): On Two Stage Least Squares Estimation of the Average Treatment Effect in a Random Coeffcient Model, Economics Letters, 56, 129-133.

Wooldridge, J. M. (2002): Econometric Analysis of Cross Section and Panel Data. MIT Press, Cambridge, MA. 


\section{Appendix}

Table 6: Summary Statistics of the Covariates

\begin{tabular}{lrr}
\hline \hline Variable & mean & std. dev. \\
\hline Age & 37.47 & 8.352 \\
Age squared & 1474 & 629.5 \\
Experience & 18.68 & 9.46 \\
Experience squared & 438.4 & 374.0 \\
Handicapped & .038 & .191 \\
Sector & & \\
Manufacturing & .318 & .466 \\
Craft & .213 & .409 \\
Trade & .103 & .303 \\
Public Service & .232 & .422 \\
Agriculture & .009 & .094 \\
Others & .120 & .325 \\
Firm size & & \\
small & .414 & .493 \\
medium & .341 & .474 \\
big & .229 & .420 \\
City size & & \\
small & .360 & .480 \\
medium & .276 & .447 \\
big & .365 & .481 \\
Federal state & & \\
Schleswig Holstein and Lower Saxony & .160 & .367 \\
Hamburg and Bremen & .033 & .180 \\
North-Rhine Westphalia & .286 & .452 \\
Rhineland-Palatinate, Hessen and & .166 & .372 \\
Baarland & & \\
West Berlin & .320 & .467 \\
Unemployment ratio & .034 & .182 \\
Number of observations & 4.16 & 2.83 \\
\hline \hline & & 7,722 \\
\hline
\end{tabular}

